\title{
Association of European Geological Societies
}

Another pan-European geoscience organization was formed recently. The Association of European Geological Societies (AEGS) joins the European Union of Geoscience and the European Federation of Geologists to link the large and diverse earth science community in Europe, spanning cultural and linguistic borders. AEGS was established by the participants of the 5th Meeting of European Geological Societies (MEGS-5) held in Dubrovnik, Yugoslavia, October $6-9,1987$. Its main purpose is to promote periodic meetings of European geologists to discuss aspects of the geology of their continent. While thus the child of MEGS, AEGS will now be the parent and sponsor of future meetings, in the same relationship as exists between IUGS and the International Geological Congresses.

Membership in AEGS is open to "all societies, institutions and organizations in Europe active on a country-wide scale in the geological or earth sciences, whether covering the entire subject field or specialising in one or more of its branches." The Association is headed by President Branislav Círić, also the President of both Geozavod (the Yugoslavian Institute for Geological and Geophysical Research) and MEGS-5. The AEGS Secretary is Mr. R.M. Bateman, Executive Secretary of the Geological Society of London (Burlington House, Piccadilly, London WIV 0JU, U.K.), which is acting as the secretariat of the new association. In approving the statutes for AEGS in Dubrovnik, the MEGS-5 participants also agreed that the new Association should seek affiliation to IUGS. $\square$

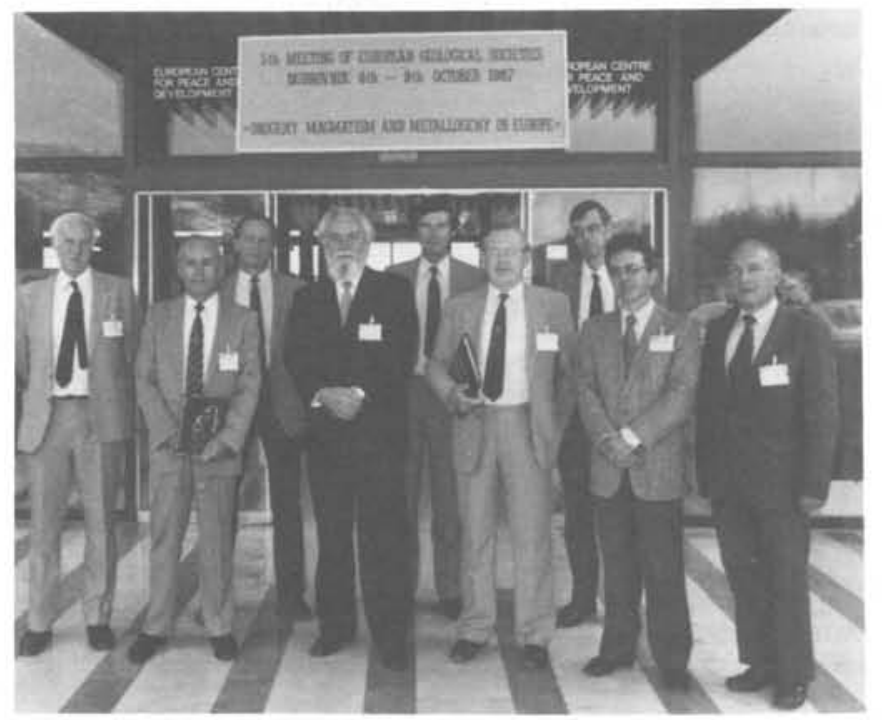

Figure 1: AEGS committee members present in Dubrovnik. L-R: J.B. Dawson (U.K.), O. Dottin (France), R. Volkov (U.S.S.R.), B. C'irić (Yugoslavia), R.M. Bateman (U.K.), N. Butcher (U.K.), A. MCMillan (U.K.), R. Rocha (Portugal) and T. Zelenka (Hungary).

\section{IUGS Launches Research Project on the Cretaceous}

The Cretaceous Period offers special opportunities for "long excursions in time and space" that can make major contributions to understanding global processes and their variations. The several transgressions of the Cretaceous left marine deposits over so much of the earth that they offer a unique opportunity to access the global synchroneity of eustasy and anoxia. This same sedimentary record also provides tests for Milankovitch rhythms, the keys to explaining the remarkably equable Cretaceous climate, and the chance to follow the development and demise of carbonate platforms.

Biologically, the Cretaceous is a turning point in the history of life for it contains the "roots" of modern grasses, reptiles, placental mammals and calcareous plankton. Cretaceous sedimentary deposits contain vast amounts of natural resources: hydrocarbons in the Middle East, Soviet Union, China and the Americas, bauxites and phosphorites in Europe and North Africa, kaolins and manganese ores in many places, and coals world-wide. Study of the Cretaceous sedimentary record on a global scale will reveal new information and concepts of processes in the oceans and atmosphere and their interaction with the biosphere. Moreover, because the Cretaceous world was so different from the modern one, an understanding of its workings could inspire some new approaches to fathom present and future processes and their results.
Against this background the IUGS Commission on Global Sedimentary Geology, recently announced the launching of the first international research project under the Global Sedimentary Geology Program (GSGP). Project CRER (Cretaceous Resources, Events and Rhythms: Global Processes and their Sedimentary Records) aims to increase understanding of the sedimentary products and the processes responsible for them during Cretaceous time. This goal will be reached through research to test the global synchroneity of various rhythms and events; to characterize and explain sedimentary deposits that are widely distributed; to analyze the global patterns of resources so as to understand better the controls on their formation and to aid in further discovery and development; and finally to seek the inter-connections between processes in the biosphere, hydrosphere, atmosphere, and lithosphere. Project CRER will also serve as a guide for subsequent GSGP Research Projects and a vehicle for promoting international exchange and training of sedimentary geologists.

Five initial Working Groups have been set up to identify research objectives and formulate plans to achieve them. Working Group 1 will address Sequence Stratigraphy and Sea Level Changes through analysis of a global network of outcrops and seismic profiles to test the concept that medium and small-seale sequences recorded globally synchronous fluctuations in sea level. 
WG-2, on Sedimentation in Oxygen-Deficient Oceans, will test the concept that the Cretaceous oceans experienced a series of anoxic events during which organic carbon-rich shales were deposited globally. This work is to be accomplished by coordinated study of the sedimentology, paleontology, geochemistry, and paleoceanography of outcrops and oceanic sections (DSDP and ODP)

WG-3 (Cyclostratigraphy) aims to test the idea that smallscale variations in bed thickness and composition of pelagic deposits are globally synchronous and the product of orbital foreing (Milankovitch rhythms).

Development and Demise of Carbonate Platforms will be addressed by WG-4 as it characterizes the growth history and anatomy of carbonate platforms and the conditions that were responsible for their abrupt decline.

WG-5, on Paleogeography, Paleoclimatology, and Sediment Flux will compile a synthesis of the changing paleogeography of the Cretaceous; validation of models of paleoclimate by comparing them with sedimentary indices of climate. WG-5 will also make an inventory of the volumes and compositions of sediments for selected time intervals.

Two Coordinating Committees will provide the all-essential time framework for the Working Groups and guidance in data management. CC-l (Geochronology) will integrate the various chronologies: biostratigraphic, radiometric, magnetic, and sequence stratigraphy. CC-2 (Data Management) will establish procedures for recording and retrieving the various kinds of data collected by the Working Groups.

Convenors for each of the Working Groups are now being named and charged with developing state-of-the-art reviews of their topics and recommending the research that is needed. The convenors will solicit comments and suggestions from colleagues world-wide and from the GSGP Committees in various countries. These reviews and recommendations for research will be distributed in Spring 1988 and will be the subject of Workshops of the individual Working Groups to be held during Summer 1988. The final reports of the Working Groups will be published in late 1988 , and they will provide the basis for planning further coordinated research by groups or individuals from various countries.

For further information, write to the GSGP Secretariat, University of Miami, Fisher Island, Miami Beach, FL 33139, U.S.A.

R.N. Ginsburg Chairman IUGS Commission for GSGP

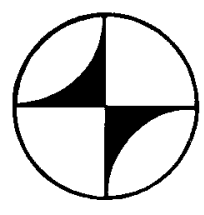

\section{New IUGG Committee on Deep Interior of the Earth}

Recognizing that significant advances in our understanding of the Earth's deep interior can best be made by combining data and theories from different geophysical disciplines, a new Union Committee to Study the Earth's Deep Interior (SEDI) was approved by the International Union of Geodesy and Geophysics at its General Assembly in Vancouver, August, 1987. The principal objective of SEDI is to encourage and facilitate cooperative studies of the structure, composition, energetics and dynamics of the deep interior, particularly the lower mantle, the core and the core-mantle boundary region. Specific problem areas of interest include: the geomagnetic dynamo and secular variation; paleomagnetism and the evolution of the Earth's deep interior; core composition, structure and dynamics; dynamo energetics and structure of the inner core; core cooling and the core-mantle boundary region; core-mantle boundary shape, coupling and the rotation of the Earth; lower-mantle structure, convection and plumes.

The officers of SEDI are E.R. Benton (U.S.A., President), D. Doornbos (Norway, Vice-President) and D. Loper (U.S.A., Secretary General), and there is also an Executive Committee representing four of the IUGG associations: IAG, IAGA, IASPEI and IAVCEI. One aim is to form country groups to encourage cooperation on a national level. Such groups have already been set up in Canada and the U.K., and one for the U.S.A. was to have been formed in December, 1987.

The first SEDI symposium is to be held at Blanes, Spain, June 23-25, 1988, in eonjunction with the Mathematical Geophysics Workshop. Other SEDI-related activities planned for the near future include a dynamo workshop, to be held near Prague, Czechoslovakia, June 27-July 1, 1988, sponsored by the Czechoslovakian Academy of Science. It is hoped that a SEDI newsletter will be started soon to inform interested scientists of upcoming meetings, new scientific developments, etc., and to provide a medium for exchange of information and ideas concerning the study of the Earth's deep interior. Anyone interested in receiving the newsletter should send their addresses to D. Loper, Geophysical Fluid Dynamics Institute, Florida State University, Tallahassee, FL 32306, U.S.A., from whom information on the SEDI meetings may also be obtained.

\section{A N N O U N C I N G}

STANDING ORDERS FOR IUGS PUBLICATIONS

IUGS is now accepting standing orders for its New Publication Series. Recent releases include "The Ordovician system of South America," "The Carboniferous of the World, Volume 2: Australia, Indian Subcontinent, South Africa, South America and North Africa," and "The Ordovician System in Kazakhstan and Middle Asia."

If you wish to receive these publications automatically as they are published, write for our standing order Agreement to Episodes, Room 177, 601 Booth St., Ottawa, Canada KlA 0E8.

DON'T RISK MISSING THESE AUTHORITATIVE PUBLICATIONS : 


\section{News Reports}

\section{World Data Center System Celebrates 30th Anniversary}

The World Data Center (WDC) system was established in 1957 , to provide archives for the data generated by the very successful International Geophysical Year. The International Council of Scientific Unions (ICSU) later invited national academies of science to establish and support WDCs for one or more disciplines, and to operate them for the benefit of international data exchange. The first two centers in the U.S.A. (WDC-A) and the U.S.S.R. (WDC-B) were subsequently joined by WDC-Cls in Western Europe, and WDC-C2s in Asia and Australasia. However, the centers are not restricted to these areas, and any qualifying national organization with the means and desire is encouraged to participate.

Duplicate centers are operated in some disciplines, to facilitate the exchange of information within certain socio-economic regions. They tend to differ in abilities and activities, partly as a reflection of the responsibilities of the host national agencies. Though this can create confusion, centers sharing responsibilities of a particular discipline maintain close contact with each other.

As an illustration, there is one grouping of WDC-A centers in Boulder Colorado: for Solid Earth Geophysics, for Marine Geology and Geophysics, for Solar-Terrestrial Physics, and for Glaciology. These are all operated by the National Geophysical Data Center (NGDC), and not surprisingly, their activities are similar to those of NGDC itself, which encourages the exchange of geoscientific data by making public-domain data in its holdings available to users for the cost of reproduction.

NGDC encourages contributions to the data pool by entitling contributors to "similar amounts" of data at no charge. In such a manner, universities, developing countries, and others without the means to purchase data can obtain such data through trade. Thus NGDC differs from private data brokers in that it deals only with data in the public domain, and that it disseminates such data on a non-profit basis.

NGDC also offers a visiting scientist program, under which free use of its data and facilities are provided for research and education, though living costs must be met by the visitor. Nearby are the University of Colorado and the Colorado School of Mines, with which NGDC has cooperative agreements, and there are many other earth science agencies and companies in the vicinity.

As part of its activities in data exchange, NGDC attempts to keep aware of major collections of geoscientific data, whether directly related to its mission or not. It maintains ties with leading individuals and agencies in its fields, participates in national and international scientific meetings, and provides advice on problems in data management and on the applications of various types of geoscientific data. NGDC also publishes maps and reports and cooperates in such ventures with others. It makes scientific analyses of data in its holdings, and helps educational institutions to utilize this data for research and teaching.

Some current areas of research at NGDC include digital data integration, data base management as a scientific research tool, quality control of data collected by others, image processing as a way of working with non-image data, and the development and application of low-cost computer

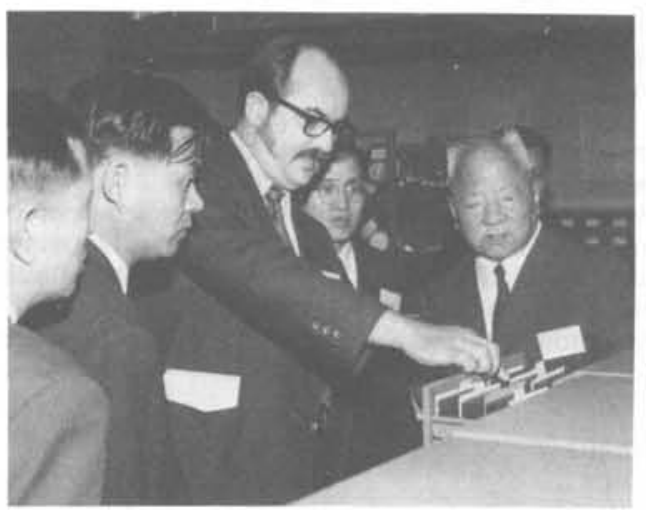

Figure 1: Chinese visitors at World Data Center-A in Boulder.

facilities for such techniques. Data most commonly utilized include that for earthquakes, tsunami, gravity, geochemistry, seismic exploration and well logs, geophysical applications of satellite altimetry, remotely sensed imagery, global elevations and bathymetry, for polar and marine regions, geomagnetism including magnetic field models, aeromagnetics and satellite magnetics, and other satellite data related to solar-terrestrial interactions. NGDC is becoming increasingly active in assisting international activities that look at the Earth as a system by providing base map information and large, integrated data bases.

In the years ahead, the World Data Centers are likely to increase their encouragement of improved data management by developing countries, of increased awareness of the scientific consequences of good (and bad) data management, of improved data integration techniques, and of regional or global studies by international groups. The centers will probably also increase their support for education and research, through the availability of useful and inexpensive data, and through greater efforts to increase the size of the pool of data available for exchange.

Much depends on the relationships between the centers and the scientific community. As the importance of data management and availability grows, WDCs will have more important roles to play, and they may spread to other areas, especially in developing nations that decide that effective data management is sufficiently important to support. However, in final analysis, the availability of (and the need for) public geoscientific data at low cost will determine the role that the centers will play in the future. Unless direct funding is provided, the financial status of the centers is likely to remain precarious.

To commemorate the 30th anniversary of the establishment of the World Data Centers, and to increase public awareness of their activities, the ICSU Panel on WDCs is publishing a series entitled a Guide to the World Data Center System. A preliminary edition of the first part of this guide is available for reference, review, and comment from the Secretariat, World Data Center-A (NOAA:E/GC2), 325 Broadway, Boulder, Colorado 80303 , U.S.A.

after report by David A. Hastings 